\title{
Accelerated Moisture Transport through Local Weakness of High-Strength Concrete Exposed to High Temperature
}

\author{
Keitai Iwama $^{1}$, Yushi Kato ${ }^{2}$, Shigeaki Baba ${ }^{2}$, Kazuaki Higuchi ${ }^{3}$ and Koichi Maekawa ${ }^{4 *}$
}

\begin{abstract}
Spilling out of condensed liquid water from needle-like holes in high-strength concrete was experimentally observed under fire attack. The presence of these holes was found to prevent explosive spalling effectively in the vicinity of the holes during fire exposure tests. This spilling out occurred at about 10 to 30 minutes after the start of high temperature heating. These needle-like holes are defined herein as local weaknesses that may act as rapid paths of water permeation to reduce the risk of explosive spalling of cover concrete. The phase change of moisture from CSH solids to condensed liquid as well as free water in micro-pores was simulated by a multi-phase chemo-physics analysis of ultra-high-strength concrete. The prediction of the high-rate phenomena was experimentally proved by using embedded moisture sensor, and the high-rate discharge of condensed water though local weaknesses was analytically simulated.
\end{abstract}

\section{Introduction}

Ultra-high-strength concrete of over $150 \mathrm{~N} / \mathrm{mm}^{2}$ has been developed (Graybeal 2006; Yoo and Yoon 2015; Abbas et al. 2016; Shafieifar et al. 2017) and applied at sites (Mitsui et al. 2010; Gosselin et al. 2016) with high performance superplasticizer and reactive fine powders (Shi et al. 2015; Wang et al. 2015). Such concrete enables us to construct super-high-rise buildings (Mitsui et al. 2010; Ninomiya et al. 2017) with reduced cross-sectional size of reinforced concrete (RC) members. In the event of fire accidents, however, the risk of explosive spalling may increase owing to the rising pressure of internal heated moisture (Kalifa et al. 2001; Phan 2008; Mindeguia et al. 2010; Jansson and Boström 2010; Ozawa et al. 2018) followed by rapid temperature rise of reinforcing bars.

Despite intensive studies on fire resistance (Kalifa et al. 2000; Bangi and Horiguchi 2012; Ozawa and Morimoto 2014; Ding et al. 2016; Li et al. 2019), there have been few investigations on localized phenomena of high strength concrete under fire attack (Markeset and Hillerborg 1995; Fujita et al. 2002; Watanabe et al. 2003). The localization of fracture has a substantial impact on

${ }^{1}$ Post doctoral fellow, Graduate School of Urban Innovation, Yokohama National University, Yokohama 240-8501, Japan.

${ }^{2}$ Researcher, Taisei Advanced Center of Technology, Taisei Corporation, Yokohama 245-0051, Japan.

${ }^{3}$ Graduate student, Department of Urban Innovation, Yokohama National University, Yokohama 240-8501, Japan.

${ }^{4}$ Professor, Department of Civil Engineering, Yokohama National University, Yokohama 240-8501, Japan.

*Corresponding author,

E-mail: maekawa-koichi-tn@ynu.ac.jp both capacity and ductility of structural concrete in general (Markeset and Hillerborg 1995; Watanabe et al. 2003), and localized damage in high strength concrete is more significant than in ordinary concrete (Fujita et al. 2002). Such brittle behavior may be associated with the explosive spalling that occurs unevenly in concrete during high temperature heating as well.

In this study, special attention was paid to needle-like holes, which appear during fire attack as shown in Fig. 1, as local weaknesses as the rapid drainage of condensed water. The water spill-out was observed at about 10 to 30 minutes after the start of high temperature heating through needle-like holes about $1 \mathrm{~mm}$ in diameter, and explosive spalling of concrete did not occur around these local weaknesses. This may be attributed to reduced pressure of moisture inside concrete (Kalifa et al. 2000, 2001; Phan 2008; Mindeguia et al. 2010; Ding et al. 2016; Ozawa et al. 2018; Li et al. 2019).

In this paper, the authors investigate the early condensation of moisture and its rapid release in the liquid phase though needle-like holes in high-strength concrete. Concrete is a porous media in which large pores to small ones are mixed and linked. Large pores play a role of chief transporting substances (Maekawa et al. 2003), and the liquid water is considered to move selectively along the larger pores. When vapor pressure inside concrete increases due to fire heating, the liquid water is thought to move through the relatively large pores. Consequently, the liquid water may seem to come out from the pinpoint, which is called needle-like hole in this paper. Although the vapor may come out through smaller pores, it cannot be visually confirmed. The previous models may have underestimated the local movement of liquid water due to the continuation of relatively large pores in an extreme condition like fire. Then in this study, the authors regard the liquid water as the characteristic event of a fire by assuming the local weakness.

Moreover, special attention was given on the extent to 
which local weaknesses affect moisture transport in the liquid phase and contribute to reduced risk of spalling. By arranging thin pipes with electrode-based moisture sensors, the condensation of liquid water, which is predicted by thermo-hygral analysis, was experimentally validated. The spill-out of condensed water is expected to improve fire resistance without reduction of compressive strength.

\section{Moisture transport under fire heating}

\subsection{Space-averaged characteristics}

The authors have upgraded the multi-scale hygro-chemophysics model (Ishida and Maekawa 1999; Maekawa et al. 2003, 2008) to allow modeling at temperatures of up to $1000^{\circ} \mathrm{C}$ (Iwama et al. 2018, 2019, 2020a). This model is practically integrated into a finite-element program. As shown in Fig. 2, this model is basically a multi-component hydration heat model that includes as components micro-structure development and degradation, moisture transport, thermodynamic equilibrium of moisture, and mass conservation. In the hygro-chemo-physics model, the degree of hydration of each mineral is calculated by the multi-component hydration heat model. According to the degree of hydration, cement hydrates are created by the micro-structure development model. The micro-structure gradually grows dense followed by a decrease in the number of capillary pores.

The strength of cementitious composites like concrete is simply assessed based upon the capillary pore porosity (Otabe and Kishi 2005). Moisture transfer is further considered in terms of vapor and liquid water migration. Here, the phase equilibrium condition is applied as the kinetic constraint of the vapor and liquid transport of moisture so that the multi-phase model may deal with both saturated and unsaturated mass transport though the micro-pores in cementitious composites. The deformation and fracture of solid skeletons are integrated with the macroscopic constitutive models of cracked concrete (Maekawa et al. 2003) according to the original framework proposed by Ishida and Maekawa (1999).

In the micro-structure development model (Ishida and
Water leakage occurs from small holes

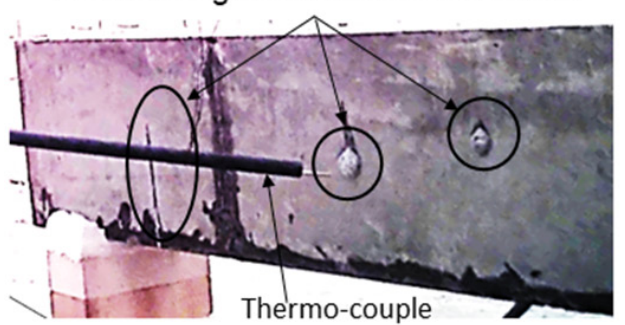

14 minutes after beginning of heating - Around $700^{\circ} \mathrm{C}$ (furnace temperature)-

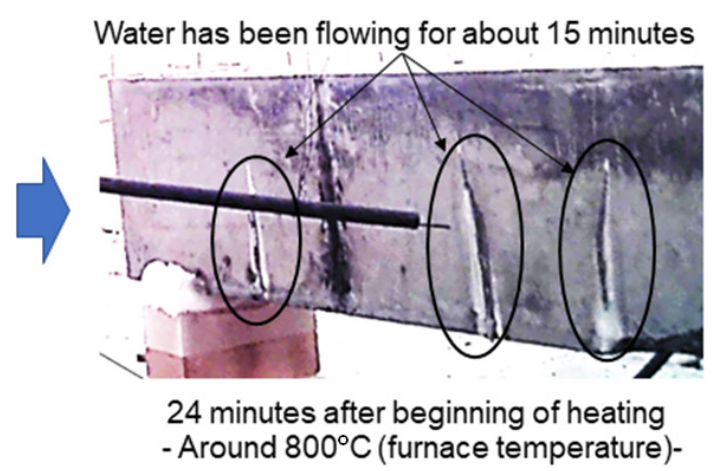

Fig. 1 Spilling out of liquid water in high-strength concrete in the early stage of heating.

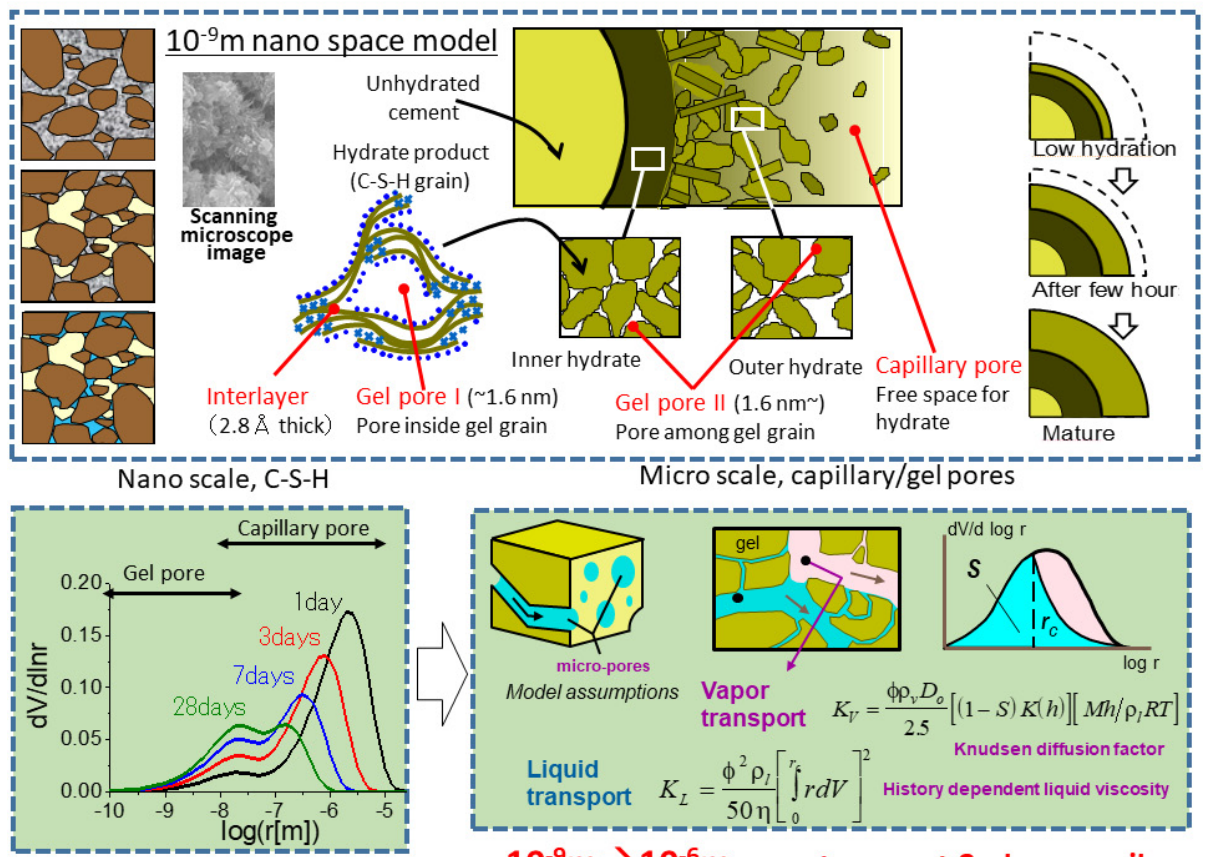

$10^{-9} \mathrm{~m} \rightarrow 10^{-6} \mathrm{~m}$ random space

$10^{-9} \mathrm{~m} \rightarrow 10^{-6} \mathrm{~m}$ mass transport \& phase equib.

Fig. 2 Outline of multi-scale hygro-chemo-physics model (Maekawa et al. 2008). 
Maekawa 1999; Maekawa et al. 2003, 2008), the overall micro-porosity distribution is statically expressed by,

$$
\phi(r)=\phi_{l r}+\phi_{g l}\left\{1-\exp \left(-B_{g l} r\right)\right\}+\phi_{c p}\left\{1-\exp \left(-B_{c p} r\right)\right\}
$$

where $\phi(r)$ is the pore size distribution to indicate the specific total pore volume whose size is less than the pore radius denoted by $r . \phi_{l r}, \phi_{g l}, \phi_{c p}$ are total porosity of interlayer, gel and capillary pores, $B_{g l}$ and $B_{c p}$ are the specific distribution parameters of gel and capillary pores, the inverse of which are representative pore sizes.

These values are formulated with respect to the specific surface area, which empirically derives from the hydration degree of cement computed by the multi-mineral heat generation model (Ishida and Maekawa 1999; Maekawa et al. 2003, 2008). In the upgraded model of high temperature (Iwama et al. 2018, $2019,2020 \mathrm{~b}$ ), the increased porosity that results from the released crystallized water is thought to be linked with the dehydration process of $\mathrm{CSH}$ solids. Consequently, the varying total porosity in concrete is expressed with the same statistical form as Eq. (1).

Based upon the calculated micro-pore structures, the moisture transport characteristics (Ishida and Maekawa 1999; Maekawa et al. 2003, 2008) are expressed as,

$$
\begin{aligned}
& K_{l}=-\frac{\rho_{l} \phi^{2}}{50 \eta}\left(\int_{0}^{r_{c}} r d V\right)^{2} \\
& K_{v}=-\frac{\phi \rho_{v} D_{0}}{2.5}[(1-S) K(h)]\left[\frac{M h}{\rho_{l} R T}\right]
\end{aligned}
$$

where $K_{l}$ is liquid conductivity $[\mathrm{kg} /(\mathrm{Pa} \cdot \mathrm{m} \cdot \mathrm{s})], \phi$ is bulk porosity of concrete, $\rho_{l}$ is density of liquid water $\left[\mathrm{kg} / \mathrm{m}^{3}\right], \quad \eta$ is actual viscosity of a fluid under non-ideal conditions $[\mathrm{Pa} \cdot \mathrm{s}], r_{c}$ is pore radius at interface of liquid and vapor [m], $r$ is pore radius [m], $K_{v}$ is vapor conductivity $[\mathrm{kg} /(\mathrm{Pa} \cdot \mathrm{m} \cdot \mathrm{s})], \quad \rho_{v}$ is density of vapor $\left[\mathrm{kg} / \mathrm{m}^{3}\right], D_{0}$ is vapor diffusivity in a free atmosphere, $S$ is saturation of porous media, $K(h)$ is Knudsen effect, $M$ is molecular weight of water $[\mathrm{kg} / \mathrm{mol}], h$ is relative humidity in the micro-pore, $R$ is gas constant $[\mathrm{J} /(\mathrm{mol} \cdot \mathrm{K})]$, and $T$ is absolute temperature $[\mathrm{K}]$.

The micro-pore structure of high-strength concrete is formed by a series of very minute pores. Since the moisture moves through these micro-pores, the moisture transfer coefficient becomes very small. Local weaknesses investigated in this paper can be assumed to be the part where relatively large pores are connected in a series of such minute pores. Water flow pipes are effective in expressing local liquid water flow in high-strength concrete, which has high moisture transfer resistance due to its dense micro-pores.

Therefore, the local weakness though which most of the condensed water may pass (Fig. 1) has been also taken into account in Eq. (2), which is originally derived from network connection among micro-pores. Espe- cially in high strength concrete with small sized micro-pores, comparatively large pores with much less volume tends to be substantial for liquid mass transport (see Appendix). Since it is hard to see the micro or meso-scale events by the space-averaged expression, one-dimensional lineal elements are introduced as fictitious thin pipes like local weakness in order to close up and focus on the local condensed water flow by integrating Eqs. (2) and (3) with the fictitious cross-sectional area of the lineal elements. It is assumed that the moisture transport in the local weakness is much faster than that in high-strength concrete. In this study, the liquid and vapor conductivity at the local weakness are simply expressed in the trial analysis as,

$$
\begin{aligned}
& K_{l, w}=1,000 K_{l} \\
& K_{v, w}=1,000 K_{v}
\end{aligned}
$$

where $K_{l, w}$ is liquid conductivity at local weakness $[\mathrm{kg} /(\mathrm{Pa} \cdot \mathrm{m} \cdot \mathrm{s})]$, and $K_{v, w}$ is vapor conductivity at local weakness $[\mathrm{kg} /(\mathrm{Pa} \cdot \mathrm{m} \cdot \mathrm{s})]$.

On the upgraded scheme (Iwama et al. 2018, 2019, $2020 \mathrm{~b}$ ), the liquid and vapor conductivities calculated in the multi-scale platform (Ishida and Maekawa 1999; Maekawa et al. 2003, 2008) are utilized at high temperatures heating. The thermodynamic phase equilibrium of the idealized vapor gas (Ishida and Maekawa 1999; Maekawa et al. 2003, 2008) is expressed as,

$$
p_{v}=P_{s a t} \cdot \exp \left(\frac{P_{l} M}{\rho_{l} R T}\right)
$$

where $p_{v}$ is vapor pressure $[\mathrm{Pa}], P_{\text {sat }}$ is the saturated vapor pressure $[\mathrm{Pa}]$, and $P_{l}$ is the pore water pressure $[\mathrm{Pa}]$. Relative humidity in the micro-pore is defined as $p_{v} / P_{\text {sat }}$.

The total stress is obtained by solving the equilibrium of solid and pore media together with the deformational compatibility and boundary conditions. If computed tensile stress exceeds its strength, cracks are assumed to occur normal to the principal stress direction. The larger the opening of the crack, the more easily the moisture migrates along the crack surface (Bazant et al. 1987; Ishida and Maekawa 1999; Maekawa et al. 2003, 2008). Moreover, in this model (Ishida and Maekawa 1999; Maekawa et al. 2003, 2008), the vapor pressure drops when crack or large volume expansion happens. When the pressure drop is great after crack occurrence, one can judge that the cracked concrete piece may leave the structural concrete by explosive spalling (Iwama et al. 2018, 2019, 2020b). Afterwards, the inside concrete volume is computationally exposed to the ambient states by progressively shifting the boundary condition (Iwama et al. 2018, 2019, 2020b).

\subsection{Local characteristics as needle-like weak- ness}

As local weakness is thought to affect overall water 
Table 1 Mix proportion of concrete in experiment and simulation.

\begin{tabular}{|c|c|c|c|c|c|c|c|}
\hline \multirow{2}{*}{ W/C (\%) } & \multirow{2}{*}{ Air (\%) } & \multicolumn{5}{|c|}{ Unit weight $\left(\mathrm{kg} / \mathrm{m}^{3}\right)$} \\
\cline { 3 - 8 } & & W & LC & BFS & SF & S \\
\hline 15.0 & 1.5 & 150 & 700 & 200 & 100 & 500 \\
\hline
\end{tabular}

W: water, LC: low-heat cement, BFS: blast furnace slag, SF: silica fume, S: fine aggregate, G: coarse aggregate

transport especially in high-strength concrete (Fig. 1), three-dimensional finite element analysis (Ishida and Maekawa 1999; Maekawa et al. 2003, 2008) was carried out with fictitious thin pipes as explained in previous sections. Structural concrete has more or less non-uniform profiles of micro-pore structures, strength, moisture states and self-equilibrated stresses under normal environments and mechanical boundaries. As the variation from the mean values of plain concrete has a minor impact on RC mechanical behaviors, one generally conducts behavioral simulation with the most probable values of the material's properties except for plain concrete.

On the other hand, mass transport is governed by the weakest component, such as construction joints and cracks, if any. Then, in order to investigate the needle-like hole computationally, the authors applied a fictitious one-dimensional finite element where the liquid conductivity $K_{l}$ and the vapor's conductivity $K_{v}$ are sufficiently large compared to continuous concrete as stated in Section 2.1. This was a kind of sensitivity analysis to discuss the sensitivity of the influencing factors. As shown in Fig. 3, the authors produced rectangular specimens with section of $300 \times 300 \mathrm{~mm}$ and height of $500 \mathrm{~mm}$, and exposed them to high temperature heating in a furnace. The water to cement ratio is $15 \%$ and the mix proportion is given in Table 1 . The specimen was demolded one day after placing, and was cured on the seal condition at $20^{\circ} \mathrm{C}$ until 28 days. After curing, the upper and lower surfaces and $100 \mathrm{~mm}$ of the side surfaces from the bottom were placed in an adiabatic condition of $20^{\circ} \mathrm{C}$. The four side surfaces were heated for 2 hours according to the ISO834 heating curve (see Fig. 3).

The locations to measure the appearance time of condensation are $75 \mathrm{~mm}$ and $150 \mathrm{~mm}$ from the heating surface and $300 \mathrm{~mm}$ from the bottom as shown in Fig. 3 . In reference to the point of spill-out from the structural concrete, a thin pipe with a moisture sensor was provided. In this study, the time when the relative humidity reaches $100 \%$ is judged as the time of condensation.

Figure 3 shows the computed relative humidity in micro-pores of concrete over time at the 75 and $150 \mathrm{~mm}$ points, and the Appendix indicates the transient profile of moisture condensation and the local moisture flux orientation in detail. The figure also shows the results of computation without assuming additional local weakness. Liquid water is computed to reach 75 and $150 \mathrm{~mm}$
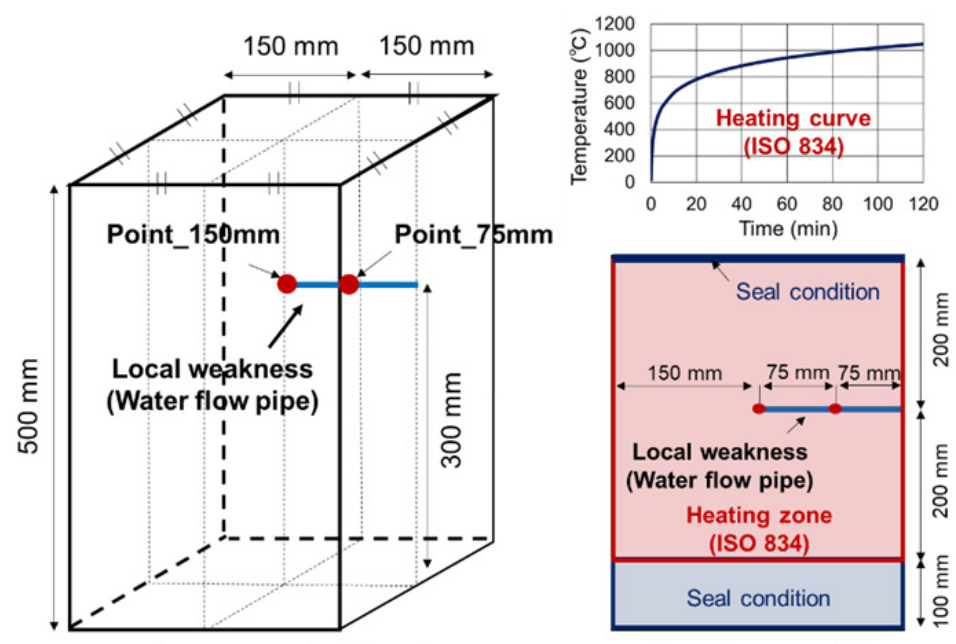

Arrangement of the pipe

Boundary conditions
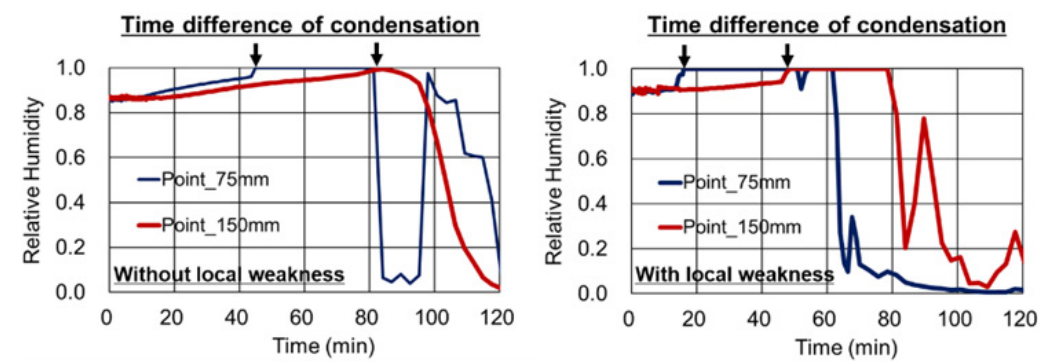

Fig. 3 Effects of local weakness on moisture transport: Analysis. 
points at approximately 40 and 80 minutes after the start of fire exposure, respectively. When concrete is assumed to be perfectly uniform in geometry (without local weakness), the vapor is simulated to go out from the surface followed by the condensed water in motion. For high-strength concrete, the micro-pore structure is extremely dense. For this reason, the front of liquefied condensation takes a long time (more than 1 hour) to reach the core center.

The lower part of Fig. 3 indicates the behavioral simulation with the local weakness as explained previously. The condensed liquid water reaches the 75 and $150 \mathrm{~mm}$ points at about 15 and 50 minutes after the start of heating. The condensation computationally appears much earlier than the case of no local weakness. When there is a local weakness through which condensed water passes easily, the surrounding moisture is corrected like tributaries flowing into the main river. Because of the extremely dense pore structures, the shortcut streamlines may play a significant role of mass transport in analysis.

\section{Validation of moisture transport}

\subsection{Experiment and monitoring of condensation}

For experimental validation of thermo-hygral multi-scale modeling at high temperature, the occurrence of condensation of moisture supplied from $\mathrm{CSH}$ solids was identified by arranging probe pipes of $10 \mathrm{~mm}$ diameter in which a moisture sensor to detect leakage of liquid water was embedded (see Fig. 4). Condensation is detected in principle by monitoring for sudden drops in electric resistance. The sensors used in the experiment to confirm the condensation are the ones to detect the arrival of moisture based on the change in conductance between a pair of electrodes. Until condensation occurs, it has high electrical resistance due to the absence of conductive liquid between the electrodes. When condensation occurs, however, an electrical path connecting the electrodes is formed and the electrical resistance decreases sharply in principle. In the sensitivity check as shown in Fig. 4, high electric resistance was maintained at about 1.0 to $3.0 \mathrm{M} \Omega$ under the relative humidity of $95 \%$, and 1 to $10 \mathrm{k} \Omega$ when the condensation occurs. This sensing capability at $100^{\circ} \mathrm{C}$ and higher was examined in advance.

Figure 5 shows the varying electric resistance over time. The heating curve is ISO834 as shown in Fig. 3. The time of condensation was judged by the sudden drop of the electric resistance. One may conclude that the condensation time is approximately 10 minutes. It was confirmed that the local weakness must be considered as an unavoidable factor in investigating the fire-resistive performance.

\subsection{Experimental verification and validation}

It was experimentally and analytically confirmed that local weakness accelerates the condensation that gradually develops inside the core of concrete. Here, let us discuss the phase change in more detail, quantitatively.

It is noted herein that the condensation at the $75 \mathrm{~mm}$ and $150 \mathrm{~mm}$ points occurs at about the same time. This coincidence cannot be computationally made with a single weakness. The authors carefully checked the possible numbers of spilling out of condensed water after the fire exposure. In fact, there exist several traces of spilling out in white as shown in Fig. 1. Then, two local weak-
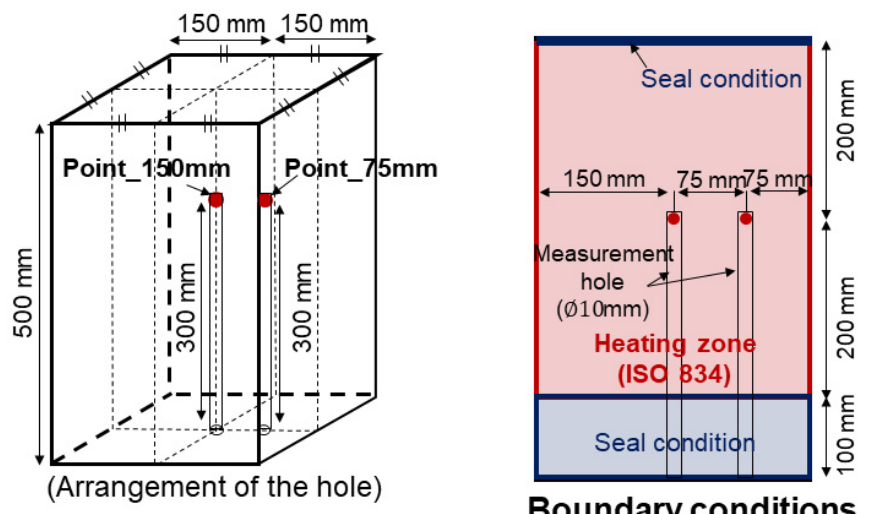

Boundary conditions
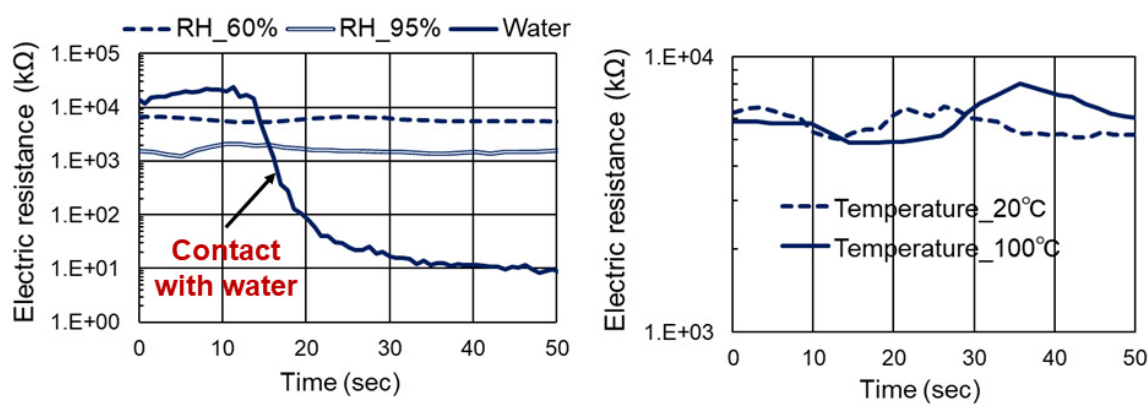

Fig. 4 Outline of experiment and sensitivity check of sensors for condensation. 
nesses (Case I and Case II: Fig. 6) were introduced for sensitivity analysis. The direction of the local weakness in Case I and Case II are the same, but the vertical location in Case II is $50 \mathrm{~mm}$ lower than that of Case I.

Figure 6 shows the simulation of RH value (S Case I and S_Case II), and the measured electric resistivity to identify the condensation time. By arranging two weak locations, the appearance time of condensation in both simulations is about 10 minutes, which is almost the same as the experiments. The liquefied condensation of moisture monitored by the sensor reaches the 75 and $150 \mathrm{~mm}$ points almost simultaneously. Accordingly, it is concluded that dispersed but multiple local weaknesses in various directions may lead to occurrence of phase
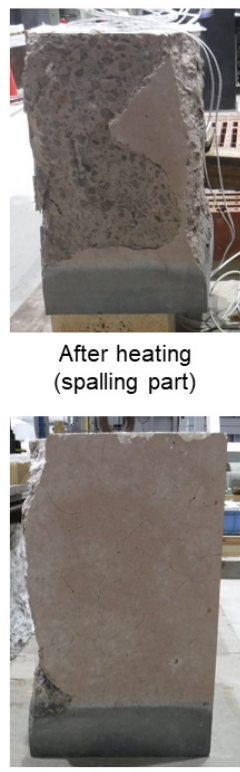

After heating (no spalling part)

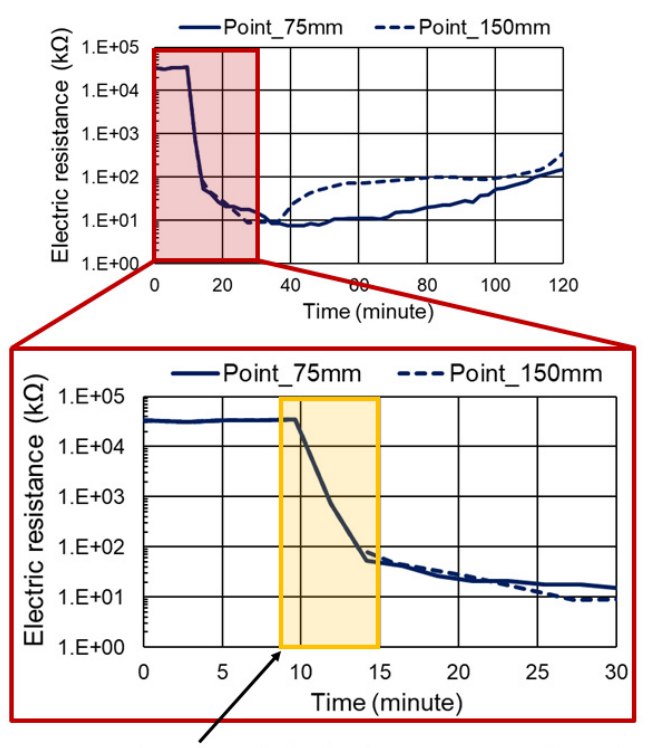

Condensation may start at both measurement points ( $75 \mathrm{~mm}$ and $150 \mathrm{~mm}$ from the heating surface)

Fig. 5 Results of arrival time of liquid water on experiment.
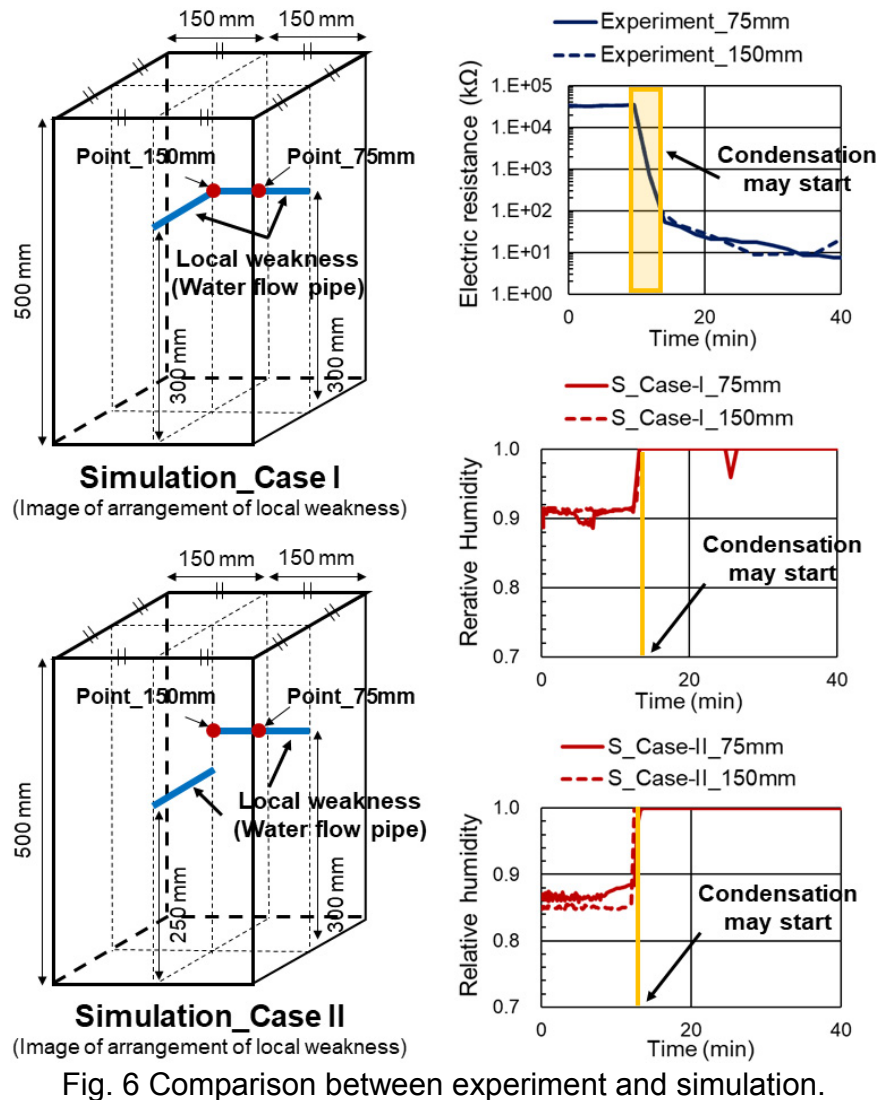

Simulation Case II

(Image of arrangement of local weakness)

Fig. 6 Comparison between experiment and simulation. 
change without time difference.

\section{Fire Resistance by Artificial Channels}

\subsection{Reduced risk of spalling by local weakness}

As shown in Figs. 1 and 5, traces of spilling out of condensed water were visually confirmed after the heating. Around the spilling marks, which were white-colored, there was no explosive spalling of concrete cover and less honeycomb cracking. Based on Boyle-Charles' law, the volume increases about 1700 times when liquid wa- ter evaporates into vapor, and this volume change has a great influence on the explosive spalling in concrete subjected to high temperature heating (Kalifa et al. 2000, 2001; Phan 2008; Mindeguia et al. 2010; Ding et al. 2016; Ozawa et al. 2018; Li et al. 2019). Provided that liquid water is also discharged quickly through needle-like holes, the risk of explosive spalling can be significantly reduced.

Next, let us look at the risk of spalling and damage of concrete associated with local weaknesses in reference to a concrete block at the $300 \mathrm{~mm}$ height. Figure 7a
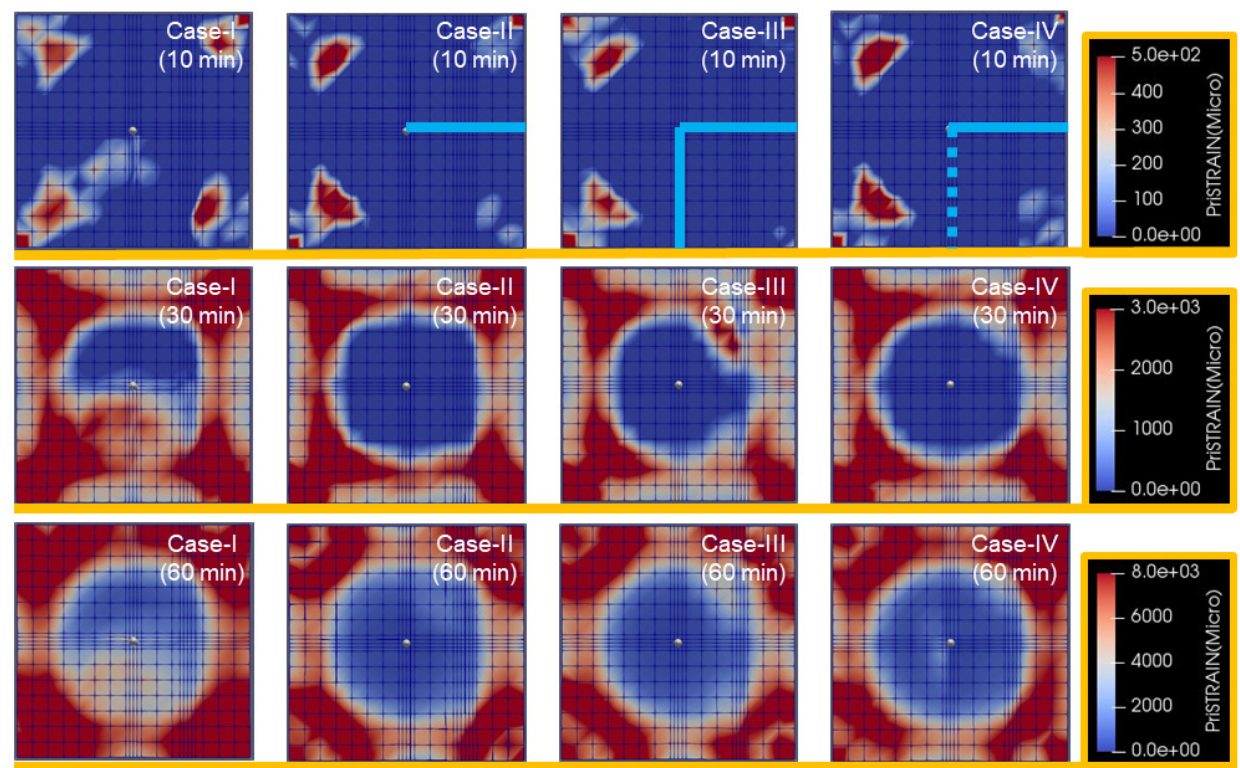

(a) Maximum principal total strain
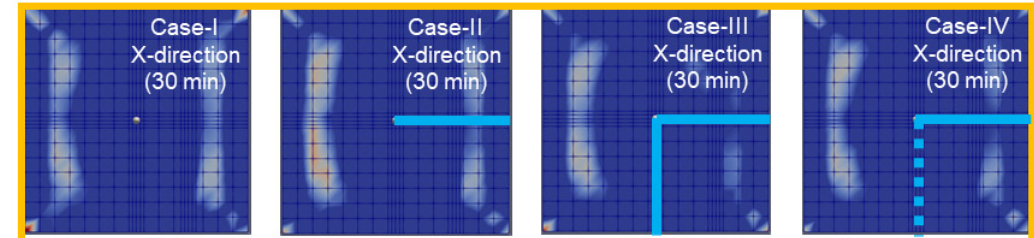

Note)

Thermal strain

is subtracted

from the total

strain so as to

clarify crack
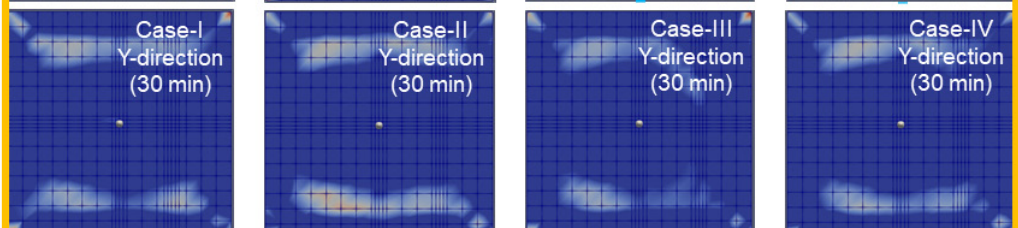

damages.

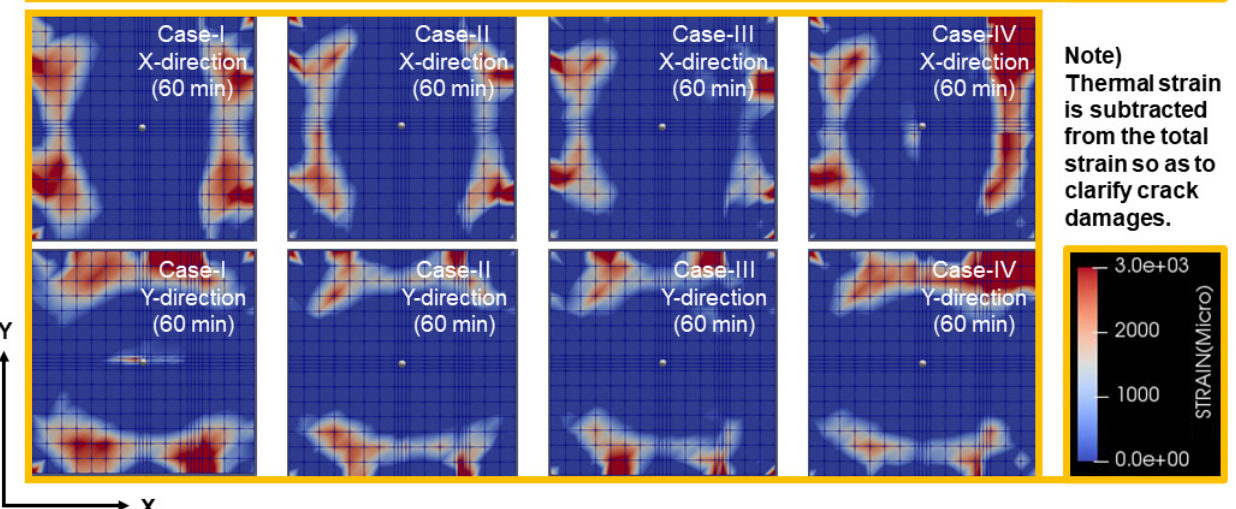

(b) Effective normal strains in $\mathrm{X}$ and $\mathrm{Y}$ directions: thermal strain is subtracted.

Fig. 7 Reduction of damage of high-strength concrete due to local weakness. 
shows the contour diagrams of the maximum principal strain (tension indicated in red) at 10, 30 and 60 minutes after fire exposure. To illustrate the strain localization more clearly, the profiles of the effective normal strains in the $\mathrm{X}$ and $\mathrm{Y}$ directions are also illustrated by subtracting the thermal expansion strain from the total strain. Case I indicates the analysis of no local weakness and Case II single local weakness, as shown in Fig. 3. Case III and Case IV in Fig. 7 correspond to the multi-directional discharge of S_Case I and S_Case II shown in Fig. 6. The solid lines in Fig. 7 indicate the locations of local weakness, and the dotted line in Case IV means shifted local weakness at $50 \mathrm{~mm}$ below the cross section.

Figure 7a shows that Case I (no local weakness, used as reference) involved the most damage, with spalling of concrete at the four corners clearly seen in the analysis. In fact, the corner parts were also lost in the experiment as shown in Fig. 5. Figure 7b illustrates the localized internal effective strain, which exceeds the cracking strain of concrete. It corresponds to spalling of the side face of the specimen in the $\mathrm{X}$ and $\mathrm{Y}$ directions.

In Cases II, III, IV, the spalling of the corner parts near the local weakness is prevented as the analysis indicates in Fig. 7a, and this approximates the reality. The concentrated strain near the local weakness is also re- duced especially in Case III with multi-directional discharge of condensed water (see Fig. 7b).

\subsection{Fire resistance of column with artificial wa- ter pipe}

As discussed in previous sections, local weakness related to condensed water may have the potential to reduce damage in high-strength concrete materials during high-temperature heating. Thus, the discussion shall be carried forward to structural concrete under external loads. The authors selected the fire resistance of a long $\mathrm{RC}$ column with artificially arranged water pipes as the target for validating the multi-scale simulation system (Ishida and Maekawa 1999; Maekawa et al. 2003, 2008; Iwama et al. 2020b).

The RC column was exposed to fire in a furnace under $30 \%$ axial compression of its static capacity (Matsudo et al. 2002; Yoshino et al. 2002, Ichise and Kawabe 2003). As shown in Fig. 8, the cross section of the column was $400 \times 400 \mathrm{~mm}$, and the length was 3600 $\mathrm{mm}$ with $2.2 \%$ longitudinal reinforcement ratio and $0.8 \%$ hoop reinforcement ratio. The RC column was made using the $35 \%$ water to binder ratio, and the thickness of the cover concrete was $40 \mathrm{~mm}$. After curing for 8 months, the entire side surfaces of the central part of the column were heated in reference to the ISO834
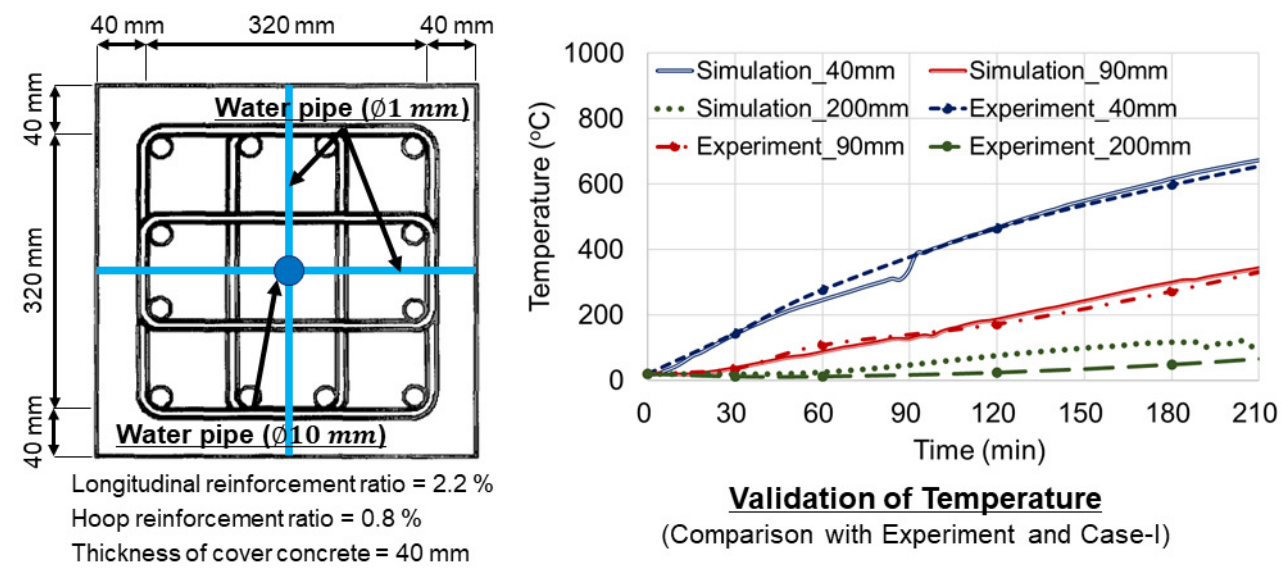

Validation of Temperature

(Comparison with Experiment and Case-I)
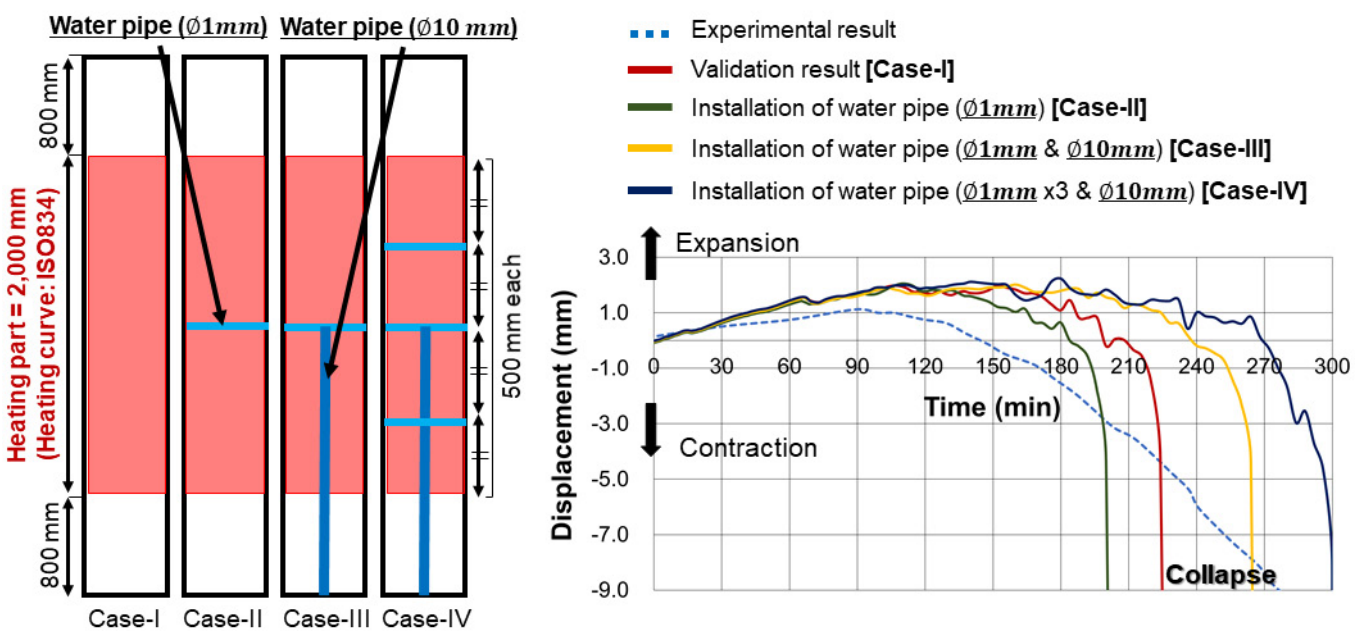

Fig. 8 Increase of fire resistance of RC column due to artificial water pipes. 
heating curve (see Fig. 8). The multi-phase hygral simulation (Iwama et al. 2019, 2020b) takes into consideration the decrease in yield strength of reinforcing bars (CEC 1990; JSCE 2004; AIJ 2009) and the varying coefficient of thermal expansion (CEC 1990; JSCE 2004; AIJ 2009).

Figure 8 shows the column deformation of the experiment and analysis (Iwama et al. 2020b). Case II is the simulation with two water pipes with diameter of 1 $\mathrm{mm}$ that cross at the center of the column height. In addition to Case II, a water pipe with diameter of $10 \mathrm{~mm}$ was added for Case III in the vertical direction for rapid discharge of water. In Case IV, water pipes with diameter of $1 \mathrm{~mm}$ were added to the configuration of Case III in the upper and lower $500 \mathrm{~mm}$ of crossed water pipes.

The temperature history of Case II inside the column was fairly reproduced and the transient deformation over time was captured qualitatively. Compared to Case I, Case II shows little early collapse accompanying restrained expansion owing to discharged water. At the same time, the broken symmetry of stress fields over the section may produce flexure to reduce the axial capacity.

However, we have less broken symmetry of the section for Case III, in which a water pipe is arranged in the vertical direction. It can be clearly seen that the burned column can resist the axially sustained compression longer than Case I. Furthermore, the higher performance of Case IV with additional water pipes can be confirmed. Without broken symmetry of thermodynamic states, the fire resistance can be improved by appropriate discharge of the condensed liquid water as well as gaseous vapor.

Non-metallic fibers are effective to improve the fire resistance of high-strength concrete in terms of the explosive spalling (Kalifa et al. 2000; Bangi and Horiguchi 2012; Ozawa and Morimoto 2014; Ding et al. 2016; Li et al. 2019), although this causes reduction in workability and compressive strength (Mitsui et al. 2010). It is also recognized that many fine cracks remain inside concrete after high temperature heating (Li et al. 2019). The mode and thermodynamic states of discharge of internal moisture pressure should be further investigated from the viewpoint of efficiency and functionality.

\section{Conclusions}

This paper reports on the investigation of the discharge of condensed water from high strength concrete members though needle-like holes under high temperature of about $1000^{\circ} \mathrm{C}$. The thermodynamic mechanism of phase change and condensation of moisture were investigated on the multi-scale thermo-hygral platform, and the following conclusions were reached.

1) Spilling out of condensed liquid water from needle-like holes was experimentally found to occur under high temperature heating in a furnace, and rapid condensation of water was experimentally confirmed.
2) Thermo-hygral analysis was conducted to investigate the mechanism of early condensation, and local weakness was assumed to function as a shortcut path of moisture transport that reduces the internal pressure of moisture released from $\mathrm{CSH}$ and $\mathrm{CH}$ solids.

3) The early discharge of condensed liquid water was further simulated to appear rapidly close to the surface of concrete and to reduce the risk of explosive spalling of cover concrete as well as the discharge of moisture in the vapor phase.

4) The effect of the spilling out of liquid water on the structural capacity of RC columns was investigated numerically in comparison with experiments under sustained loads of high temperature, and it was pointed out that pointwise local moisture loss of the liquid as well as gaseous phases though local weakness plays a substantial role on the suppression of explosive spalling of cover concrete.

\section{Acknowledgements}

This study was supported by JSPS KAKENHI Grant Number 20H00260.

\section{References}

Abbas, S., Nehdi, M. L. and Saleem, M. A., (2016). "Ultra-high performance concrete: Mechanical performance, durability, sustainability and implementation challenges." International Journal of Concrete Structures and Materials, 10, 271-295.

AIJ, (2009). "Guide book for fire-resistive performance of structural materials." Tokyo: Architectural Institute of Japan and Maruzen Publishing . (in Japanese)

Bangi, M. R. and Horiguchi, T., (2012). "Effect of fiber type and geometry on maximum pore pressures in fiber-reinforced high strength concrete at elevated temperatures." Cement and Concrete Research, 42(2), 459-466.

Bazant, Z. P., Sener, S. and Kim, J. K., (1987). "Effect of cracking on drying permeability and diffusivity of concrete." ACI Materials Journal, 84(5), 351-357.

CEC, (1990). "Eurocode 4, Design of composite structures - Part 10: Structural fire design." Brussels: Commission of European Communities.

Ding, Y., Zhang, C., Cao, M., Zhang, Y. and Azevedo, C., (2016). "Influence of different fibers on the change of pore pressure of self-consolidating concrete exposed to fire." Construction and Building Materials, 113, 456-469.

Fujita, M., Sato, R., Matsumoto, K. and Takaki, Y., (2002). "Size effect on shear strength of RC beams using HSC without shear reinforcement." Doboku Gakkai Ronbunshu, 711/V-56, 161-172. (in Japanese)

Ghafari, E., Costa, H., Júlio, E., Portugal, A. and Durães, L., (2014). "The effect of nano-silica addition on flowability, strength and transport properties of ultra high performance concrete." Materials \& Design, 59, $1-9$.

Gosselin, C., Duballet, R., Roux, P. H., Gaudillière, N., 
Dirrenberger, J. and Morel, P. H., (2016). "Large-scale 3D printing of ultra-high performance concrete - A new processing route for architects and builders." Materials \& Design, 100, 102-109.

Graybeal, B. A., (2006). "Material property characterization of ultra-high performance concrete." Washington, D.C.: Office of Infrastructure Research and Development, Federal Highway Administration.

Ichise, K. and Kawabe, S., (2003). "Analytical study on deformation property of reinforced concrete columns using high-strength concrete during a fire." Journal of Structural and Construction Engineering (Transactions of AIJ), 68(568), 1-6. (in Japanese)

Ishida, T. and Maekawa, K., (1999). "An integrated computational system of mass/energy generation, transport and mechanics of materials and structures." Doboku Gakkai Ronbunshu, 627/V-44, 13-25. (in Japanese)

Iwama, K., Ishibashi, N. and Maekawa, K., (2018). "Modeling of decomposition and self-healing processes of hardened cement paste exposed to high temperature." In: B. Chen and J. Wei Eds. The 8th International Conference of Asian Concrete Federation, Fuzhou, China 4-7 November 2018. Pathumani, Thailand: Asian Concrete Federation, 227-234.

Iwama, K., Higuchi, K. and Maekawa, K., (2019). "Multi-scale modeling of deteriorating concrete at elevated temperature and collapse simulation of underground ducts." In: G. Pijaudier-Cabot, P. Grassl and C. La Borderie, Eds. Proc. 10th International Conference on Fracture Mechanics of Concrete and Concrete Structures, Bayonne, France 23-26 June 2019.

Iwama, K., Higuchi, K. and Maekawa, K., (2020a). "Model-based assessment of long-term serviceability and fire resistance for underground reinforced concrete ducts." Structural Engineering International, 30(4), 506-514.

Iwama, K., Higuchi, K. and Maekawa, K., (2020b). "Thermo-mechanistic multi-scale modeling of structural concrete at high temperature." Journal of Advanced Concrete Technology, 18(5), 272-293.

Jansson, R. and Boström, L., (2010). "The influence of pressure in the pore system on fire spalling of concrete." Fire Technology, 46, 217-230.

JSCE, (2004). "Report on fire resistance technology for concrete structures." Tokyo: Japan Society of Civil Engineers. (in Japanese)

Kalifa, P., Menneteau, F. D. and Quenard, D., (2000). "Spalling and pore pressure in HPC at high temperatures." Cement and Concrete Research, 30(12), 1915-1927.

Kalifa, P., Chéné, G. and Gallé, C., (2001). "High-temperature behavior of HPC with polypropylene fibers: From spalling to microstructure." Cement and Concrete Research, 31(10), 1487-1499.

Li, Y., Pimienta, P., Pinoteau, N. and Tan, K. H., (2019). "Effect of aggregate size and inclusion of polypropylene and steel fibers on explosive spalling and pore pressure in ultra-high-performance concrete (UHPC) at elevated temperature." Cement and Concrete Composites, 99, 62-71.

Li, Y., Zhang, Y., Yang, E. H. and Tan, K. H., (2019). "Effects of geometry and fraction of polypropylene fibers on permeability of ultra-high performance concrete after heat exposure." Cement and Concrete Research, 116, 168-178.

Maekawa, K., Ishida, T. and Kishi, T., (2003). "Multi-scale modeling of concrete performance - Integrated material and structural mechanics (Invited)." Journal of Advanced Concrete Technology, 1(2), 91-126.

Maekawa, K., Pimanmas, A. and Okamura, H., (2003). "Nonlinear mechanics of reinforced concrete." London and New York: Spon Press.

Maekawa, K., Ishida, T. and Kishi, T., (2008). "Multi-scale modeling of structural concrete." London: Taylor \& Francis.

Markeset, G. and Hillerborg, A., (1995). "Softening of concrete in compression - Localization and size effects." Cement and Concrete Research, 25(4), 702-708.

Matsudo, M., Yoshino, S., Wakamatsu, T., Kondo, S., Sasaki, H., Hirashima, T., Yoshida, M., Uesugi, H. and Saito, H., (2002). "Study on fire resistance of reinforced concrete columns with ultra high strength material (Part 1 Outline of fire resistance test under load)." In: Summaries of Technical Papers of Annual Meeting of AIJ, Ishikawa, Japan 1-4 August 2002. Tokyo: Architectural Institute of Japan, 21-22. (in Japanese)

Mindeguia, J. C., Pimienta, P., Noumowé, A. and Kanema, M., (2010). "Temperature, pore pressure and mass variation of concrete subjected to high temperature - Experimental and numerical discussion on spalling risk." Cement and Concrete Research, 40(3), 477-487.

Mitsui, K., Kojima, M., Yonezawa, T., Sugata, M. and Mihashi H., (2010). "Development of 150-200 N/mm² high strength concrete with hybrid fiber and application to a building structure." AIJ Journal of Technology and Design, 16(32), 21-26. (in Japanese)

Ninomiya, T., Sugimura, M., Yoshino, Y. and Komuro, T., (2017). "Design and construction of the super high-rise building with deep underground structure." Concrete Journal, 55(6), 523-528.

Otabe, Y. and Kishi, T., (2005). "Development of hydration and strength model for quality evaluation of concrete." Industrial Science (University of Tokyo), 57(2), 37-42. (in Japanese)

Ozawa, M. and Morimoto, H., (2014). "Effects of various fibers on high-temperature spalling in high-performance concrete." Construction and Building Materials, 71, 83-92.

Ozawa, M., Tanibe, T., Kamata, R., Uchida, Y., Ryokugo, K. and Parajuli, S. S., (2018). "Behavior of ring-restrained high-performance concrete under extreme heating and development of screening test." Construction and Building Materials, 162, 215-228.

Phan, L. T., (2008). "Pore pressure and explosive spalling in concrete." Materials and Structures, 41, 1623-1632. 
Shafieifar, M., Farzad, M. and Azizinamini, A., (2017). "Experimental and numerical study on mechanical properties of ultra high performance concrete (UHPC)." Construction and Building Materials, 156, 402-411.

Shi, C., Wu, Z., Xiao, J., Wang, D., Huang, Z. and Fang, Z., (2015). "A review on ultra high performance concrete: Part I. Raw materials and mixture design." Construction and Building Materials, 101(1), 741-751.

Wang, D., Shi, C., Wu, Z., Xiao, J., Huang, Z. and Fang, Z., (2015). "A review on ultra high performance concrete: Part II. Hydration, microstructure and properties." Construction and Building Materials, 96, 368-377.

Watanabe, K., Niwa, J., Yokota, H. and Iwatani, M., (2003). "Formation of stress-strain relationship of concrete

\section{Appendix}

\section{Non-stationary internal moisture state and formed band of wet condensation}

Figure A1 shows the computed location of condensation of liquid water inside the concrete specimen. Just after the exposure of elevated temperature, the moisture is lost from the surface and the water content of concrete close to the surface is reduced. However, inside the concrete specimen, crystalized water is released from the $\mathrm{CSH}$ and $\mathrm{CH}$ solids by the temperature elevation, resulting in the condensation of water. This band of condensation where the relative humidity is $100 \%$ shifts considering the localized compressive failure zone." Doboku Gakkai Ronbunshu, 725/V-58, 197-211. (in Japanese)

Yoo, D. Y. and Yoon, Y. S., (2015). "Structural performance of ultra-high-performance concrete beams with different steel fibers." Engineering Structures, 102, 409-423.

Yoshino, S., Matsudo, M., Kikuta, S., Takahashi, K., Inoue, T., Hirashima, T., Yoshida, M., Uesugi, H. and Saito, H., (2002). "Study on fire resistance of reinforced concrete columns with ultra high strength material (Part 2 Results of fire resistance test under load)." In: Summaries of Technical Papers of Annual Meeting of AIJ, Ishikawa, Japan 1-4 August 2002. Tokyo: Architectural Institute of Japan, 23-24. (in Japanese) to the core center of the square cross-section. For the case of the lower strength concrete, the size of condensation band gets wider owing to easier permeation though larger sized micro-pores, and the liquid pressure inside the condensation band is comparatively less than the one of high strength concrete. Since the condensation band is created closer to the surface at the early stage of fire exposure, the spill-out of condensed water may easily form when the short-cut pipe would be created as discussed in Section 2.2.

For normal strength concrete with $\mathrm{W} / \mathrm{C}=55 \%$, the half of the condensed water denoted by P in Fig. A1 computationally flows through micro-pore spaces as Eq. (2)

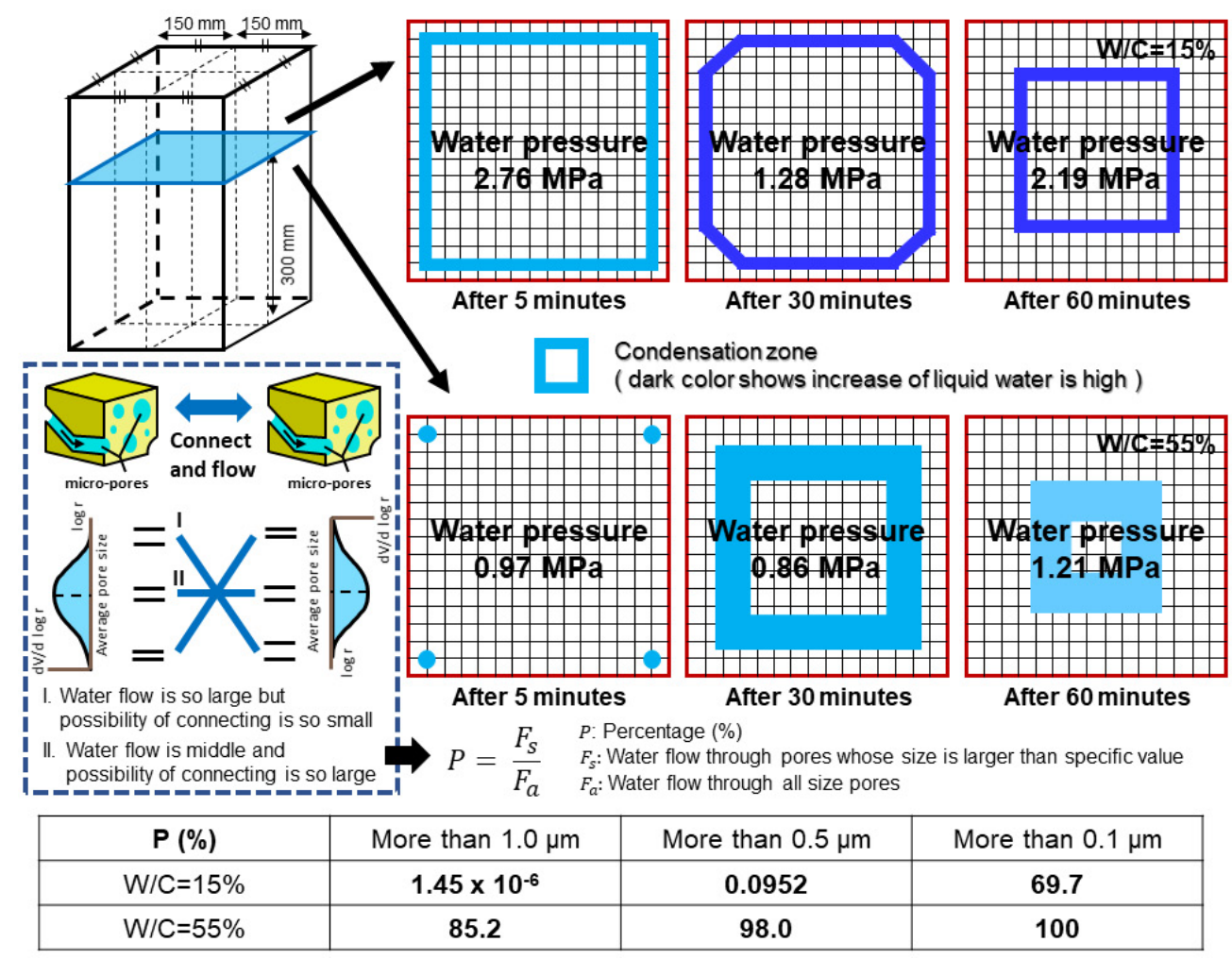

Fig. A1 Computed transient profile of condensed water inside concrete specimen. 


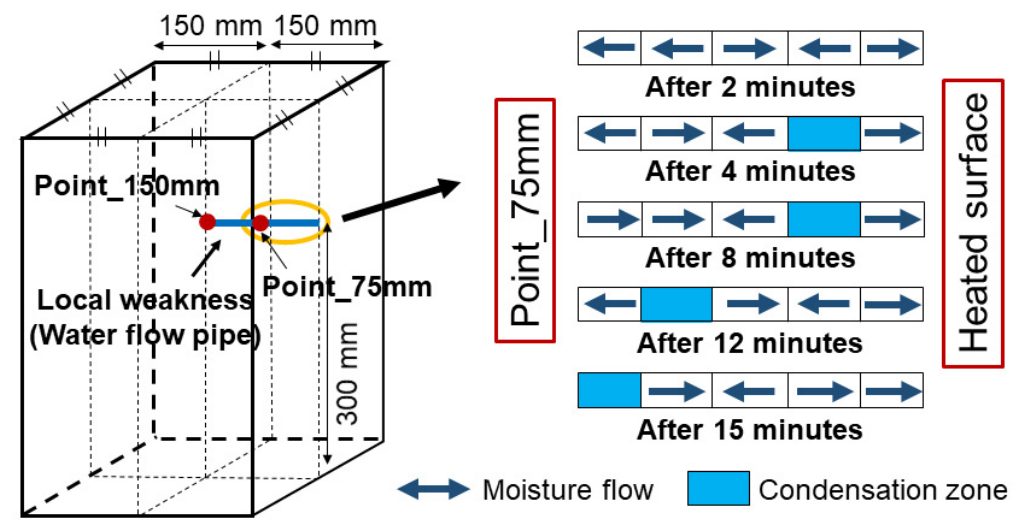

Fig. A2 Computed flow direction of moisture flux and condensation zone.

whose size is more than $1.8 \mu \mathrm{m}$ and its volume is only $1.8 \%$ of the whole micro-pores (Maekawa et al. 2008). Here, the referential factors of $B_{g l}$ and $B_{c p}$ in Eq. (1) are $0.61 \times 10^{8}[1 / \mathrm{m}]$ and $0.26 \times 10^{8}[1 / \mathrm{m}]$, which corresponds to the time at testing.

It means that the liquid condensed water is mainly conveyed though large pores of very small volume. This tendency is much stronger for the high strength concrete like $\mathrm{W} / \mathrm{C}=15 \%$, where $0.74 \%$ volume with $0.135 \mu \mathrm{m}$ or more in which $B_{g l}$ and $B_{c p}$ are $0.15 \times 10^{9}[1 / \mathrm{m}]$ and $0.20 \times 10^{7}[1 / \mathrm{m}]$, respectively. As shown in Fig. A1, the ratio of condensed water flux though the micro-pores of different sizes is indicated. For high strength concrete of so small pore sizes, most condensed water is discharged though larger sized pores of extremely small volume.
Figure A2 shows the location of condensation with liquefied water and the direction of moisture flux along the transverse direction. It must be noted that the local flux of moisture is not in one-way but in complexity. The left and right wings of the condensation zone have the opposite direction of the moisture flux, since the higher water pressure drives the local dispersion of moisture to both outside and inside direction of the specimen. At the same time, the vaporized water of gaseous phase is in motion according to the pressure gradient, which is also affected by the water condensation, which produces the sudden drops of vapor pressure itself. Thus, the band of condensation shifts to the core center of the specimen. 